IJADR

International Journal of Alcohol and Drug Research

The Official Journal of the Kettil Bruun Society for Social and Epidemiological Research on Alcohol

doi: 10.7895/ijadr.v4i2.212

IJADR, 2015, 4(2), $101-102$

ISSN: 1925-7066

\title{
Commentary: Girls, women, and alcohol: Implications for alcohol policy
}

\author{
Ann Dowsett Johnston \\ Winner of five gold National Magazine Awards, is a respected journalist with more than 30 years of experience in national media. Winner of the \\ Atkinson Fellowship in Public Policy (Women and Alcohol), she is the bestselling author of Drink: The intimate relationship between women and \\ alcohol (Harper Collins).
}

Alcohol abuse is rising in much of the developed world, and in many countries, female drinkers are responsible for this growth. This is a global issue: the richer the country, the fewer abstainers and the smaller the gap between male and female behaviour. The new reality: while male consumption is constant or declining, female consumption is on the upswing.

Where will it stop? This question has epidemiologists scratching their heads. Women occupy the lion's share of postsecondary spots in the Western world. Those with a university degree are almost twice as likely to drink daily as those without. Those in high-status occupations, working in male-dominated environments, have an increased risk of alcohol-use disorders. In fact, the one protective factor for women? Low-status, blue-collar occupations.

In writing my recent book Drink: The Intimate Relationship Between Women and Alcohol, my primary question was: why are women playing catch-up with men? My conclusions are three-fold.

Number one: I believe that alcohol is the modern women's steroid, enabling her to do the heavy lifting involved in a complex, demanding world. Racing home from demanding jobs, heading into the night shift of looking after households and family, we reach for the handiest decompression tool. It's now the female prerogative to drink, and to drink daily.

Number two: self-medication. Women are $40 \%$ more likely than men to suffer from depression than men. We suffer more anxiety. We often drink to numb, drink to escape, drink to forget.

Number three: we romance the glass, and marketing has played a huge role in this. In the past two decades, an entire feminized drinking industry has been groomed to woo us. Think alcopops, those sweet pre-packaged vodkaor rum-infused starter drinks, also known as "chick beer." Think Skinnygirl Vodka, Mommyjuice wine, berryflavored vodka.
These aren't manly drinks. No, the alcohol industry looked at market segmentation and realized that an entire gender had been under-served. Now, we have our very own alcohol products: sweet, pretty, and pink. On university campuses, when drinking games are played, he's drinking beer, she's doing shots. She's two-thirds his size and may not have eaten. Excessive drinking has come to represent gender equality. This is a real-time natural experimentand it's gendered.

Are we having an adult conversation about women and alcohol? The answer is a resounding "no."

This dialogue should begin with an open conversation about the health implications of risky drinking. Politically, we are equal. But hormonally and metabolically, we are different when it comes to alcohol. And this has implications over the long run. Female chemistry means we become dependent much faster than men. Cognitive deficits, liver disease, and other consequences all occur earlier, with significantly less exposure. Heavy drinkers of both sexes run the risk of a fatal hemorraghic stroke, but the odds are five times higher for women. Alcoholism is a more serious risk for early mortality than smoking-and more than twice as deadly for women as for men. Meanwhile, according to the Toronto's Centre on Addiction and Mental Health, up to $15 \%$ of breast cancer cases can be attributed to alcohol consumption.

Policies, laws, and the broader social context all contribute substantially to our drinking habits. Clearly, there is a need for specific public health prevention and intervention efforts. We have solid evidence that widespread risky drinking is costly. We also have solid evidence that key policy levers can influence this picture. The three strongest: regulating price, restricting the accessibility of alcohol, and limiting marketing. Press on those levers and you can shift consumption. You can also tackle some other major problems along the way: alcohol taxes are easy to administer, and can cover many shortfalls in cash-strapped times. 
But society has to want to make those shifts-and to do so, we have to be clear about our values. At its very essence, public policy is the result of a simple equation: evidence plus values plus politics equals policy. We have solid evidence that widespread risky drinking is costly. But let's face it: when it comes to alcohol, our values are a little fuzzy. Virtually all of us know someone with an alcohol problem. But at a cultural level, we tend to "other" the problem: it's the rare alcoholic, the drunk driver, the guy on the street corner swigging from the brown paper bag. And if it's our own problem? Well, we're just trying to drink like the French or the Italians-imbibing in the name of sophistication.

Policy shifts can cause seismic cultural and environmental shifts. This is well documented. Look at drunk driving. Look at tobacco control. But as the seasoned California activist Jim Mosher says: "With tobacco, it was easier. We eradicated the product. With alcohol, you want to manage it. But politics are so driven by special interests - and money. We don't have the power base to counter the strategic lobbying of the alcohol industry."

Solid evidence plus fuzzy values and political indifference adds up to inaction-inaction for which women may pay a bigger price than men. We are disproportionately likely to suffer the health and social effects of alcohol abuse, to suffer from interpersonal violence, including sexual assaults. We are definitely prone to the secondhand effects of excessive consumption. We need a comprehensive public health response, and we need it fast. 